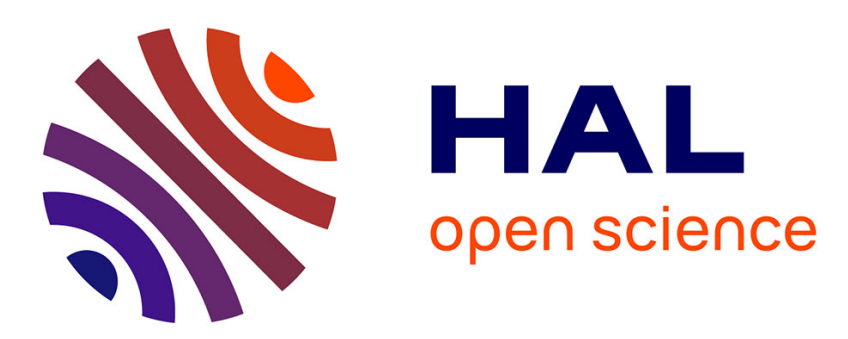

\title{
Reply: Treatment of anti-MDA5 autoantibody-positive juvenile dermatomyositis using tofacitinib
}

Olivier Benveniste, Yves Allenbach, Océane Landon-Cardinal

\section{To cite this version:}

Olivier Benveniste, Yves Allenbach, Océane Landon-Cardinal. Reply: Treatment of anti-MDA5 autoantibody-positive juvenile dermatomyositis using tofacitinib. Brain - A Journal of Neurology , 2019, 142 (11), pp.e60-e60. 10.1093/brain/awz294 . hal-03523494

\section{HAL Id: hal-03523494 \\ https://hal.sorbonne-universite.fr/hal-03523494}

Submitted on 12 Jan 2022

HAL is a multi-disciplinary open access archive for the deposit and dissemination of scientific research documents, whether they are published or not. The documents may come from teaching and research institutions in France or abroad, or from public or private research centers.
L'archive ouverte pluridisciplinaire HAL, est destinée au dépôt et à la diffusion de documents scientifiques de niveau recherche, publiés ou non, émanant des établissements d'enseignement et de recherche français ou étrangers, des laboratoires publics ou privés. 


\title{
Reply: Treatment of anti-MDA5 autoantibody-positive juvenile dermatomyositis using tofacitinib
}

\author{
Océane Landon-Cardinal, ${ }^{1,2,3}$ Olivier Benveniste ${ }^{1,2}$ and Yves Allenbach ${ }^{1,2}$
}

1 Department of Internal Medicine and Clinical Immunology, Pitié-Salpêtrière University Hospital, Assistance Publique-Hôpitaux de Paris, East Paris Neuromuscular Diseases Reference Center, Inserm U974, Sorbonne Université, Paris 6, Paris, France

2 Department of Inflammation, Immunopathology and Biotherapy (I2B), Pitié-Salpêtrière University Hospital, Assistance PubliqueHôpitaux de Paris, East Paris Neuromuscular Diseases Reference Center, Inserm U974, Sorbonne Université, Paris 6, Paris, France

3 Department of Medicine, University of Montreal; Division of Rheumatology and Research Center, Centre Hospitalier de l’Université de Montréal, Montreal, Quebec, Canada

Correspondence to: Yves Allenbach

Department of Internal Medicine and Clinical Immunology, Pitié-Salpêtrière University

Hospital, 47-83 Boulevard de l'Hôpital, 75013 Paris, France

E-mail: yves.allenbach@aphp.fr

Sir,

In their letter, Sabbagh et al. report two refractory juvenile dermatomyositis (DM) patients with anti-MDA5 autoantibodies who significantly improved muscle and skin but also lung disease, following treatment with a Janus Kinase 1 and 3 (JAK 1/3) inhibitor (tofacitinib). This observation extends case reports published previously (Aeschlimann et al., 2018; Papadopoulou et al., 2019) reporting the improvement in two other refractory juvenile DM (JDM) cases using another JAK inhibitor (baricitinib).

The rationale of JAK inhibitor use is supported by the strong interferon (IFN) pathway activation in the peripheral blood, muscle and skin biopsies (Wong et al., 2012; Huard et al., 2017; Uruha et al., 2017) of DM patients and the demonstration in vitro of the pathogenic role of IFN on both vascular and muscular cells (Ladislau et al., 2018). Indeed, the JAK family plays an important role in the intracellular signalling of multiple cytokines including IFN signalling transduction (Schwartz et al., 2017).

Importantly, Sabbagh et al. report for the first time the successful effect of tofacitinib in two cases of anti-MDA5 JDM associated with interstitial lung disease (ILD). This observation is in line with previously published cases in adult anti-MDA5 DM patients (Kurasawa et al., 2018; Kato et al., 2019).

Severe ILD in anti-MDA5 JDM patients has been reported in East-Asian patients (Sato et al., 2009;
Kobayashi et al., 2015) and is associated with poor prognosis. In juvenile Caucasian populations, a lower frequency of milder ILD has been reported (Tansley et al., 2014). Nonetheless, the cases reported by Sabbagh et al. illustrate that severe ILD in anti-MDA5 JDM can occur and underlines the necessity of finding therapeutic options for these cases at high risk of morbidity and fatality.

A few cases of anti-MDA5 JDM patients associated with severe ILD have also been observed in our cohort and these cases are challenging to manage. Since our publication (Ladislau et al., 2018), we have treated four adult antiMDA5 DM patients with JAK inhibitors. We only observed a limited beneficial effect. Indeed, only a single patient improved, while three others worsened and died of respiratory failure in the intensive care unit (ICU). Of note, two of these four patients were treated when they were already in respiratory failure in the ICU. One of them improved and was successfully weaned off the noninvasive ventilation, while the other died. These observations raise the question whether the use of JAK inhibitors earlier may have prevented the development of respiratory failure in the presence of anti-MDA5 ILD.

Anti-MDA5 DM has also been associated with a severe vasculopathy (Fiorentino et al., 2011). We previously demonstrated in vitro that endothelial cells exposure to type I IFN disrupted vascular network organization and 
this effect was reversed by JAK inhibitor therapy (Ladislau et al., 2018). Interestingly, the second patient reported by Sabbagh et al. demonstrated a complete resolution of digital ulcers following tofacitinib.

An association between calcinosis and the presence of vascular injury has also been reported (Wendel et al., 2019). Along that line, it must be underlined that the second JDM case displayed an improvement of the calcinosis. Of note, the absence of progression of calcification was reported in other JDM patients treated with JAK inhibitor (Aeschlimann et al., 2018; Papadopoulou et al., 2019). Nonetheless, this is the first JDM case reporting an improvement of calcinosis. Similarly, two other adult DM cases treated with tofacitinib were recently reported and also demonstrated an improvement of extensive calcifications (Valenzuela et al., 2014).

Sabbagh et al. demonstrated that in both patients treated with tofacitinib, STAT1 phosphorylation in CD4 + T cells and monocytes stimulated with multiple cytokines (IFN $\alpha$, IL-6, IL-21, and IFN $\gamma$ ) improved to levels comparable to healthy controls, showing the broader immunomodulatory effect of JAK inhibition other than type I IFN (Schwartz et al., 2017). The pathomechanisms involved in the ILD of anti-MDA5 DM remain to be clarified, and the report of Sabbagh et al. suggest the presence of several putative pathways may be involved in addition to IFN-induced lung injuries (e.g. vascular damages) (Liu et al., 2014).

This broad effect of JAK inhibitors is also reflected by its efficacy in many other inflammatory diseases that are not IFN-dependent such as rheumatoid arthritis, psoriasis and psoriatic arthritis and ulcerative colitis (Schwartz et al., 2017). Of note, one of the patients reported by Sabbagh et al. developed herpes simplex meningitis following tofacitinib. Prospective trials are needed to clarify the infection risk and safety profile associated with these molecules especially in refractory DM patients previously exposed to several lines of immunosuppressants (Cohen et al., 2014).

If JAK inhibitors take advantage of the important number of cytokines mediating signals via the JAK-STAT pathway to control immune responses, one must not forget that JAK-STAT pathway is also involved in non-immune systems. In the context of juvenile patients, one must consider that JAK2 also transduces the growth hormone signals (Brooks et al., 2014; Schwartz et al., 2017). Nonetheless, previously published cases have not reported growth delays in children treated with JAK inhibitors for JDM or genetic interferonopathies (Frémond et al., 2016; Aeschlimann et al., 2018; Sanchez et al., 2018; Papadopoulou et al., 2019).

To conclude, JAK inhibitors represent a promising therapeutic option for the treatment of juvenile and adult DM. Emerging data suggest its potential beneficial effect on calcinosis and anti-MDA5 related ILD. Prospective clinical trials are needed to confirm these encouraging observations.

\section{Data availability}

The data that support the findings of this study are available from the corresponding author, upon reasonable request.

\section{Competing interests}

The authors report no competing interests.

\section{References}

Aeschlimann FA, Frémond M-L, Duffy D, Rice GI, Charuel J-L, Bondet $\mathrm{V}$, et al. A child with severe juvenile dermatomyositis treated with ruxolitinib. Brain J Neurol 2018; 141: e80.

Brooks AJ, Dai W, O’Mara ML, Abankwa D, Chhabra Y, Pelekanos RA, et al. Mechanism of activation of protein kinase JAK2 by the growth hormone receptor. Science 2014; 344: 1249783.

Cohen S, Radominski SC, Gomez-Reino JJ, Wang L, Krishnaswami S, Wood SP, et al. Analysis of infections and all-cause mortality in phase II, phase III, and long-term extension studies of tofacitinib in patients with rheumatoid arthritis. Arthritis Rheumatol 2014; 66: 2924-37.

Fiorentino D, Chung L, Zwerner J, Rosen A, Casciola-Rosen L. The mucocutaneous and systemic phenotype of dermatomyositis patients with antibodies to MDA5 (CADM-140): a retrospective study. J Am Acad Dermatol 2011; 65: 25-34.

Frémond M-L, Rodero MP, Jeremiah N, Belot A, Jeziorski E, Duffy D, et al. Efficacy of the Janus kinase $1 / 2$ inhibitor ruxolitinib in the treatment of vasculopathy associated with TMEM173-activating mutations in 3 children. J Allergy Clin Immunol 2016; 138: 1752-5.

Huard C, Gullà SV, Bennett DV, Coyle AJ, Vleugels RA, Greenberg SA. Correlation of cutaneous disease activity with type 1 interferon gene signature and interferon $\beta$ in dermatomyositis. Br J Dermatol 2017; 176: 1224-30.

Kato M, Ikeda K, Kageyama T, Kasuya T, Kumagai T, Furuya H, et al. Successful treatment for refractory interstitial lung disease and pneumomediastinum with multidisciplinary therapy including tofacitinib in a patient with anti-MDA5 antibody-positive dermatomyositis. J Clin Rheumatol Pract Rep Rheum Musculoskelet Dis 2019.

Kobayashi N, Takezaki S, Kobayashi I, Iwata N, Mori M, Nagai K, et al. Clinical and laboratory features of fatal rapidly progressive interstitial lung disease associated with juvenile dermatomyositis. Rheumatology 2015; 54: 784-91.

Kurasawa K, Arai S, Namiki Y, Tanaka A, Takamura Y, Owada T, et al. Tofacitinib for refractory interstitial lung diseases in anti-melanoma differentiation-associated 5 gene antibody-positive dermatomyositis. Rheumatology (Oxford) 2018; 57: 2114-9.

Ladislau L, Suárez-Calvet X, Toquet S, Landon-Cardinal O, Amelin D, Depp M, et al. JAK inhibitor improves type I interferon induced damage: proof of concept in dermatomyositis. Brain J Neurol 2018; 141: 1609-21.

Liu Y, Jesus AA, Marrero B, Yang D, Ramsey SE, Sanchez GAM, et al. Activated STING in a vascular and pulmonary syndrome. N Engl J Med 2014; 371: 507-18.

Papadopoulou C, Hong Y, Omoyinmi E, Brogan PA, Eleftheriou D. Janus kinase $1 / 2$ inhibition with baricitinib in the treatment of juvenile dermatomyositis. Brain 2019; 142: e8.

Sanchez GAM, Reinhardt A, Ramsey S, Wittkowski H, Hashkes PJ, Berkun Y, et al. JAK1/2 inhibition with baricitinib in the treatment of autoinflammatory interferonopathies. J Clin Invest 2018; 128 : $3041-52$. 
Sato S, Hoshino K, Satoh T, Fujita T, Kawakami Y, Fujita T, et al. RNA helicase encoded by melanoma differentiation-associated gene 5 is a major autoantigen in patients with clinically amyopathic dermatomyositis: association with rapidly progressive interstitial lung disease. Arthritis Rheum 2009; 60: 2193 200.

Schwartz DM, Kanno Y, Villarino A, Ward M, Gadina M, O'Shea JJ. JAK inhibition as a therapeutic strategy for immune and inflammatory diseases. Nat Rev Drug Discov 2017; 16: 843-62.

Tansley SL, Betteridge ZE, Gunawardena H, Jacques TS, Owens CM, Pilkington C, et al. Anti-MDA5 autoantibodies in juvenile dermatomyositis identify a distinct clinical phenotype: a prospective cohort study. Arthritis Res Ther 2014; 16: R138.
Uruha A, Nishikawa A, Tsuburaya RS, Hamanaka K, Kuwana M, Watanabe Y, et al. Sarcoplasmic MxA expression: a valuable marker of dermatomyositis. Neurology 2017; 88: 493-500.

Valenzuela A, Chung L, Casciola-Rosen L, Fiorentino D. Identification of clinical features and autoantibodies associated with calcinosis in dermatomyositis. JAMA Dermatol 2014; 150: 724.

Wendel S, Venhoff N, Frye BC, May AM, Agarwal P, Rizzi M, et al. Successful treatment of extensive calcifications and acute pulmonary involvement in dermatomyositis with the Janus-Kinase inhibitor tofacitinib-a report of two cases. J Autoimmun 2019; 100: 131-6.

Wong D, Kea B, Pesich R, Higgs BW, Zhu W, Brown P, et al. Interferon and biologic signatures in dermatomyositis skin: specificity and heterogeneity across diseases. PLoS ONE 2012; 7: e29161. 